\title{
Financial Development and Inequality in the Global Economy
}

\author{
CRED Research Paper No. 8
}

\author{
Maximilian von Ehrlich \\ University of Bern, \\ CRED
}

Tobias Seidel

University of Duisburg-Essen

\begin{abstract}
We build a heterogeneous-firms model with firm-specific wages and credit frictions to study the role of financial development for inequality in the global economy. If there are many small firms, better access to external funds reduces wage inequality and unemployment. In contrast, if there are many highproductive firms (those that export), financial development may have opposite effects - especially if trade costs are low. In sum, the implications of financial development for inequality depend on the size distribution of firms and on the costs of exporting. Trade liberalization, however, raises inequality unambiguously.
\end{abstract}

Key words: financial development, credit constraints, international trade, inequality.

JEL classification: F160, F650 


\section{Center for Regional Economic Development (CRED)}

University of Bern

Schanzeneckstrasse 1

P.O.Box 8573

CH-3001 Bern

Telephone: +41316313711

Fax: +41316313415

E-Mail: info@,cred.unibe.ch

Website: http://www.cred.unibe.ch

The Center for Regional Economic Development (CRED) is an interdisciplinary hub for the scientific analysis of questions of regional economic development. The Center encompasses an association of scientists dedicated to examining regional development from an economic, geographic and business perspective.

\section{Contact of the authors:}

Maximilian von Ehrlich

University of Bern

Schanzeneckstrasse 1

P.O.Box 8573

CH-3001 Bern

Telephone: +41316318075

Email: maximilian.vonehrlich@,vwi.unibe.ch

Tobias Seidel

University of Duisburg-Essen

Lotharstraße 65

D-47057 Duisburg

Telephone: +49 (203) 379 - 2625

Email: tobias.seidel@uni-due.de 


\section{Introduction}

Financial markets have grown rapidly over the last decades, especially in high-income countries. Looking at the United States and Great Britain, for example, the ratio of private credit relative to GDP has increased from a value of about one in the 1980s to around two in recent years. ${ }^{1}$ Similar trends arise in France or Germany, albeit at lower levels. ${ }^{2}$ Parallel to this trend, world trade has grown about twice as fast as global production since the 1980s (WTO, 2013). A third stylized fact that is characteristic for many economies is the rise of income inequality, especially within skill groups (see, e.g. Katz and Autor, 1999, or Autor, Katz, and Kearney, 2008).

While there has been some effort to link trade integration to wage inequality, the implications of financial development for the wage distribution and unemployment are less well understood, especially in the global economy. We therefore build a model to make progress in this direction. Our model features three types of frictions to rationalize the stylized facts introduced above. First, moral hazard in credit markets leads to credit rationing. As contracts cannot be written contingent on entrepreneurial effort, lenders demand a sufficiently high entrepreneurial stake in the project to render shirking unattractive. Otherwise, a project fails with certainty and the lender loses the investment. Capital owners are endowed with one unit of assets, but differ in their entrepreneurial skill to run a firm. As higher skill translates into higher total factor productivity and thus higher profits, entrepreneurs of low-productivity firms do not earn enough to credibly commit to diligent behavior. As a consequence, lenders do not grant external finance causing credit rationing of those firms. In essence, credit frictions affect the distribution of firms by excluding the least-productive enterprises from external finance and thus entry. This mechanism is in line with empirical evidence that small firms benefit most from financial development. Aghion, Fally, and Scarpetta (2007) show for 16 industrialized and emerging economies that "access to finance matters most for the entry of small firms". ${ }^{3}$

Second, there is a friction in the labor market. We assume that workers have fairness preferences where firm-specific operating profits serve as the reference income for determin-

\footnotetext{
${ }^{1}$ World Bank Global Financial Development Database.

${ }^{2}$ Alternative measures like market capitalization show a similar picture.

${ }^{3}$ Further evidence is provided by Beck, Demirgüç-Kunt, Laeven, and Levine (2008), or Beck, DemirgüçKunt, and Maksimovic (2005).
} 
ing the individual fair wage. ${ }^{4}$ Due to firm heterogeneity, more productive firms pay higher wages giving rise to a skill-group-specific wage distribution (see Egger and Kreickemeier, 2009, 2012). Apart from being a simple tool to rationalize firm-specific wages, Howitt (2002) and Bewley (2005) have provided sound evidence for this mechanism. Third, international trade is inhibited by both variable and fixed trade costs. This leads to selection of the most productive companies into exporting (Melitz, 2003). Overall, the model allows us to compare the effects of both trade liberalization and financial development for the distribution of wages and unemployment.

Financial development is modelled as a reduction in agency costs such that lowproductivity firms get access to external finance to enter the market. This can be achieved, for example, by an improvement in institutions like investor protection or law enforcement. In autarky, financial development leads to firm entry and a lower unemployment rate, but has no effect on the ratio between average and marginal wages in our model. In the open economy, in contrast, relative wages respond to financial development because the change in both the number of firms and the share of exporters alters the wage distribution. While better access to external finance exerts ambiguous effects on wage inequality in general, we show that financial development reduces inequality if there are relatively more small (low productive) firms. Financial development amplifies wage inequality, however, if the size distribution of firms is more homogeneous and the costs of exporting are low. This ambiguity roots in two effects. First, better access to finance stimulates entry of small firms. Ceteris paribus, this broadens the range of productivities and firm-specific wages such that inequality would increase. Second, entry of small firms leads to a reduction of market shares of incumbent firms and a reduction in the share of exporters which compresses both the wage schedule and the average wage. The relative size of these effects depends on the prevalence of small versus large firms and the propensity to export. ${ }^{5}$

Looking at trade liberalization, we find that a marginal reduction in trade costs raises wage inequality and unemployment. ${ }^{6}$ The different effects of financial development and trade liberalization root in differences in firm selection. While financial development leads to more entry of small firms and a lower share of exporters (Ehrlich and Seidel, 2015),

\footnotetext{
${ }^{4}$ See Akerlof and Yellen (1990).

${ }^{5} \mathrm{~A}$ number of papers have provided reduced-form evidence that financial development reduces inequality, e.g. Clarke, Xu, and Zou (2006), Liang (2006), Beck, Demirgüç-Kunt and Levine (2007).

${ }^{6}$ This result is well understood from several papers in the trade-and-labor literature. For example, Egger and Kreickemeier (2012) have shown that a marginal reduction of trade costs raises inequality when the share of exporters is low.
} 
trade liberalization stimulates entry into exporting and reduces the number of firms in one country (Krugman, 1979, Melitz, 2003).

Our paper relates to at least three strands of literatures. First, recent work on the effects of globalization for income inequality concludes that goods market integration tends to raise inequality in several dimensions (e.g. Amiti and Davis, 2012; Egger and Kreickemeier, 2009, 2012; Helpman and Itskhoki, 2010; Helpman, Itskhoki, and Redding; 2010; Sampson, 2014), but it is silent about the role of financial market development. Second, seminal finance papers by Galor and Zeira (1993) and Banerjee and Newman (1993) argue that financial development raises investment opportunities of the poor exerting an equity-enhancing effect. ${ }^{7}$ Our paper deviates by focussing on firm selection in the global economy as a so far unexplored mechanism in this context. Third, a recent and growing literature has studied the role of financial frictions for the pattern of international trade (e.g. Antràs and Foley, 2015, Egger and Keuschnigg, 2015, Manova, 2008, 2013, Schmidt-Eisenlohr, 2013), but offers no insights with respect to inequality.

A paper that considers financial frictions, globalization, and inequality in one framework is Foellmi and Oechslin (2010). The authors assume that entrepreneurs are equipped with heterogeneous endowments of capital in a less developed economy and show that trade leads to more inequality between entrepreneurs. Our paper differs as we are focusing on the role of financial development for wage inequality in the global economy. We look at two symmetric economies and take up no stance on the degree of economic development.

The paper is organized as follows. We start with a non-technical overview of the model. Section 3 introduces the closed-economy model in detail before we extend the framework to two symmetric countries in section 4 . Section 5 offers concluding remarks.

\section{Overview}

Before we start with the formal analysis, we provide a brief overview of the model and introduce some of the basic notation. There are two identical economies inhabited by two groups of individuals: Production workers $L$ possessing one efficiency unit of labor each and risk-neutral capitalists owning one unit of assets $A$ each. Capitalists differ in their innate entrepreneurial skill $\varphi$. The economy accommodates two industries: An intermediate

\footnotetext{
${ }^{7}$ Further examples on finance and inequality include Acemoglu and Zilibotti (1997) and Matsuyama (2004)
} 
Figure 1: TIMELINE

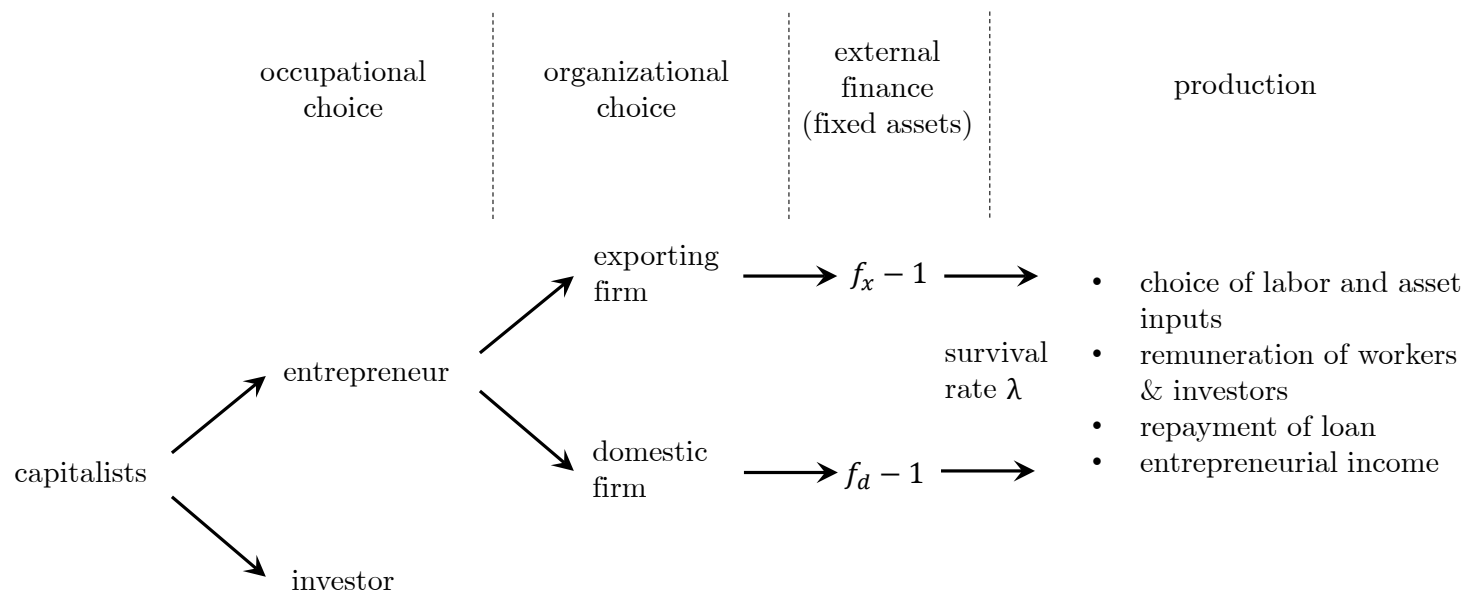

goods industry that produces unique varieties $(q)$ which are aggregated according to CEStechnology to the homogeneous final good $Y$ at zero cost. The final good sector operates under perfect competition.

Figure 1 illustrates the sequencing of decisions in the model. Capitalists initially choose between a career as an entrepreneur and an investor. Those with a sufficiently high $\varphi$ find it profitable to run a firm as their entrepreneurial skill translates into total factor productivity of the company. Entrepreneurs further need to choose the organizational form of their firm. Exporting requires additional fixed costs such that only the most skilled entrepreneurs are able to make profits from serving the foreign market in addition. While domestic firms require $f_{d}$ units of assets, exporters need $f_{x}$ units of assets to cover fixed costs for both domestic and exporting operations.

Entrepreneurs need to secure external finance to start production. However, the asset market is subject to a financial friction because the effort of the entrepreneur is unobservable to third parties and contracts cannot be written contingent on the behavior of the entrepreneur. As firms are only economically viable under diligent behavior, investors require a sufficiently large entrepreneurial income to render shirking unattractive. Thus, the financial friction prevents capitalists with a too low $\varphi$ from entering the market as entrepreneurs. Importantly, credit rationing only occurs at the low end of the productivity distribution because exporters make sufficiently large profits ensuring diligent behavior. 
Hence, the financial friction governs firm entry and the export propensity. These selection effects are at the heart of the economic mechanism in our model. A fraction $1-\lambda$ of those who were successful in securing external finance are hit by a bad shock that prevents them from producing. Surviving firms hire workers and assets as variable inputs, produce and sell their goods in the respective market(s). It is important to stress that fairwage preferences avoid market clearing on the labor market and give rise to firm-specific wages. Finally, all investors are remunerated. In the next section, we introduce the closedeconomy version of this model (without organizational choice). Section 3 introduces all relevant building blocks for the closed economy in detail. We expand the model to the two-country case in section 4 .

\section{The closed economy}

\subsection{Goods markets}

The economy produces two types of goods, a homogeneous final good $Y$ and a set $V$ of intermediate goods. The latter serve as inputs in the production of the final good according to

$$
Y=\left[M^{-(1-\alpha)} \int_{v \in V} q(v)^{\alpha} d v\right]^{1 / \alpha}, \quad 0<\alpha<1 .
$$

The quantity of the intermediate input variety $v$ is denoted by $q(v), M$ represents the mass of available intermediates that will be determined endogenously in equilibrium and $\alpha$ is a parameter that governs the elasticity of substitution between varieties, $\sigma=1 /(1-\alpha)$. We choose $Y$ as the numeraire and impose perfect competition in the final goods market such that the price of the homogeneous good is normalized to one. Profit-maximizing demand for intermediate good $v$ is then given by

$$
q(v)=\frac{Y}{M} p(v)^{-\sigma}
$$

where $p(v)$ denotes the price of this intermediate.

We assume that capitalists differ in their entrepreneurial skills $\varphi$ that for the sake of convenience equals total factor productivity in case they run a firm. Combining assets and labor according to Cobb-Douglas technology then delivers $q(\varphi)=\varphi l(\varphi)^{\mu} a(\varphi)^{1-\mu}$, where $l$ 
and $a$ are firm-specific labor and asset inputs (per efficiency unit). Firms maximize profits by charging a constant mark-up over marginal costs such that

$$
p(\varphi)=\frac{[\gamma w(\varphi) / \varepsilon(\varphi)]^{\mu}}{\alpha \varphi}
$$

where $w(\varphi) / \varepsilon(\varphi)$ represents wages per efficiency unit and $\gamma$ is the standard Cobb-Douglas cost parameter. ${ }^{8}$ Cobb-Douglas technology ensures that the cost shares of labor and capital are constant and given by $\mu$ and $1-\mu$, respectively. Note that we make use of the simplifying assumption that assets and final goods are perfectly substitutable. This implies that the price of assets is pinned down to unity as well and does not show up explicitly in the pricing equation above. This assumption reduces the complexity of expressions substantially. Firm revenues are given by $r(\varphi)=(Y / M) p(\varphi)^{1-\sigma}$. Due to constant markup pricing, operating profits are a constant fraction $1 / \sigma$ of revenues.

\subsection{Labor market}

To introduce firm-specific wages into our model, we follow Egger and Kreickemeier (2012) by assuming that workers have fairness preferences. ${ }^{9}$ The fair wage $\hat{w}$ is determined according to

$$
\hat{w}(\varphi)=\left[\frac{r(\varphi)}{\sigma}\right]^{\theta}[(1-U) \bar{w}]^{1-\theta},
$$

where the first part denotes operating profits and the second one the expected wage income outside the firm ( $U$ is the unemployment rate, $\bar{w}$ the average wage of employed workers). The parameter $\theta \in(0,1)$ is referred to as the fair-wage parameter describing the relative importance of each component in the fair-wage equation. Higher values of $\theta$ indicate stronger preferences for a more equal split of firm income between entrepreneurs and workers and thus more rigid labor markets.

Notice that workers from low-productivity firms or without employment are willing to underbid (fair) wages of employees at high-productivity firms, as detailed in Egger and Kreickemeier (2012). However, these firms do not have an incentive to accept those bids as they would imply lower effort of workers and thus no advantage for them. ${ }^{10}$

\footnotetext{
${ }^{8} \mathrm{It}$ is given by $\gamma=\left(\frac{\mu}{1-\mu}\right)^{1-\mu}\left(\frac{1-\mu}{\mu}\right)^{\mu}$.

${ }^{9}$ The approach goes back to seminal work by Akerlof and Yellen (1990). An alternative to rationalize firm-specific wages is 'search and matching' as used by e.g. Helpman, Itskhoki, and Redding (2010).

${ }^{10}$ Fehr and Falk (1999) as well as Howitt (2002) and Bewley (2005) are relevant sources for evidence on
} 
Relating the fair-wage constraint and revenues of firms with different productivities establishes

$$
\frac{r\left(\varphi_{1}\right)}{r\left(\varphi_{2}\right)}=\left(\frac{\varphi_{1}}{\varphi_{2}}\right)^{\eta} \quad \text { and } \quad \frac{w\left(\varphi_{1}\right)}{w\left(\varphi_{2}\right)}=\left(\frac{\varphi_{1}}{\varphi_{2}}\right)^{\theta \eta},
$$

where $\eta \equiv(\sigma-1) /[1+\theta \mu(\sigma-1)]$ reflects the elasticity of firm revenues with respect to firm level productivity. This reveals that firms with higher total factor productivity make higher operating profits and pay higher wages.

Finally, we need to rationalize why firms do not pay less than the fair wage, especially as some workers are unemployed and those working for less productive firms receive lower wages. This is achieved by assuming that workers reduce their effort $\varepsilon$ proportionally if they are paid less than the fair wage. Thus, firms cannot increase their profits by paying lower wages and we can safely assume that each firm pays the fair wage, so $w=\hat{w}$. This implies that every worker supplies the maximum effort level $\varepsilon=1$.

\subsection{Asset market}

To start production, firms have to invest $f_{d}>1$ units of assets that cannot be financed through cash flows. As each entrepreneur is endowed with one unit herself, $f_{d}-1$ units have to be secured on the asset market. However, asymmetric information between borrowers and lenders give rise to a financial friction in the tradition of Holmstrom and Tirole (1997). Entrepreneurs can choose their effort to run their firm which is unobservable for third parties and cannot be inferred from the firm's profits or revenues. Assuming that projects only have positive net present values when the entrepreneur behaves, lenders have to ensure that shirking is never an appealing option to avoid losses on average.

All firms are subject to bad shocks that imply no revenues from the endeavor - independent of the entrepreneur's behavior. However, diligent behavior reduces the probability of being hit by the bad shock such that the success rate $\lambda_{b}>0$ exceeds the success rate under shirking $\lambda_{s}=0$. We follow Ju and Wei (2011) in interpreting $\lambda$ as a property rights protection index.

The incentive compatibility $(I C)$ constraint postulates that the expected income of entrepreneurs from running the firm must be higher under diligent behavior than under shirking. Entrepreneurs receive operating profits minus the repayment to the bank, $T$, this mechanism. 
such that

$$
\lambda\left[\frac{r(\varphi)}{\sigma}-T\right] \geq b
$$

where $b$ measures the private benefit of shirking denoted in units of the numeraire and can be regarded as an inverse measure of corporate governance. Thus, the magnitude of this agency cost parameter is determined by the quality of institutions like investor protection or rule of law. We can infer from (IC) that the pledgable income results as $r(\varphi) / \sigma-$ $b / \lambda$. To ensure participation of investors in the endeavor, the expected pledgable income has to exceed the credit volume. This ensures that the entrepreneur behaves diligently and generates a sufficiently high income to repay the loan. Formally, this participation constraint is given by

$$
\lambda\left[\frac{r(\varphi)}{\sigma}-\frac{b}{\lambda}\right] \geq f_{d}-1
$$

As operating profits are increasing in productivity $\varphi$, the condition that identifies the marginal entrepreneur receiving external finance reads

$$
\lambda \frac{r\left(\varphi^{*}\right)}{\sigma}=f_{d}-1+b
$$

As managers borrow from a perfectly-competitive financial sector, they offer the minimum repayment that meets (IC), that is $T=\left(f_{d}-1\right) / \lambda$. Hence, the entrepreneur receives the entire surplus if the project is funded. Notice that entrepreneurs have an incentive to invest their endowment in their own firm.

\subsection{Occupational choice}

Capitalists choose between a career as investors and entrepreneurs. Due to heterogeneous managerial abilities, expected incomes from running a firm varies. For the sake of simplicity, we assume that this ability translates exactly to total factor productivity of the company such that we can identify the indifference condition of capitalists as follows:

$$
\lambda\left[\frac{r(\varphi)}{\sigma}-\frac{f_{d}-1}{\lambda}\right] \geq 1 .
$$

An asset owner founds a firm if his expected profits (left-hand side) exceed the safe return on assets that we have normalized to one (right-hand side). 


\subsection{Equilibrium factor allocation}

As we are interested in the implications of financial development, that is a reduction in agency cost parameter $b$, we need to ensure that the participation constraint is binding. Comparing (PC) and (OC) yields the sufficient condition $b>1$. This implies that there are capital owners that could earn expected profits larger than one by running a firm, but cannot enter the market due to credit rationing. Their income would be too low to credibly commit to diligent behavior.

We rearrange the participation constraint by using two convenient relationships. First, the sum of operating profits in the intermediate goods industry is given by $(1-\alpha) Y$ in our case of constant markup pricing. Second, we assume that entrepreneurial skills and thus firm productivities follow a Pareto distribution. Specifically, we normalize the scale parameter to unity to get $G(\varphi)=1-\varphi^{-k}$, where $k$ represents the shape parameter. High values of $k$ indicate high densities of low-productivity firms. We will use the convenient insight that the average productivity $\tilde{\varphi}$ (determined by $q(\tilde{\varphi})=Y / M$ ) is proportional to the productivity cutoff $\varphi^{*}$,

$$
\tilde{\varphi}=\left(\frac{k}{k-\eta}\right)^{1 / \eta} \varphi^{*}
$$

where we impose the parameter constraint $k>\eta$. With this information at hand, we reformulate the participation constraint in the following way,

$$
\frac{(1-\alpha) Y}{M^{e}} \frac{k-\eta}{k}=f_{d}-1+b,
$$

where we have substituted the number of firms $M$ by the number of entrants $M^{e}$ using $M=\lambda M^{e}$. Further, we can replace $Y$ by exploiting the fact that the return to assets used as variable inputs is given by $A^{v}=\alpha(1-\mu) Y$.

The resource constraint for assets establishes a second equation linking $A^{v}$ and the number of entering firms $M^{e}$. It is obtained as ${ }^{11}$

$$
A^{v}=A-M^{e} f_{d} .
$$

\footnotetext{
${ }^{11}$ Note that we assume here that capital invested in firms that are hit by the bad shock cannot be used as a variable input in other firms. It is straightforward to relax this assumption so a fraction of invested capital can be used for variable investment in other. This would not affect results qualitatively (see Ehrlich and Seidel, 2015).
} 
Using both equations delivers

$$
\begin{aligned}
A^{v} & =\frac{k(\sigma-1)\left(f_{d}-1+b\right)(1-\mu)}{k(\sigma-1)\left(f_{d}-1+b\right)(1-\mu)+f_{d}(k-\eta)} A, \\
M^{e} & =\frac{k-\eta}{k(\sigma-1)\left(f_{d}-1+b\right)(1-\mu)+f_{d}(k-\eta)} A .
\end{aligned}
$$

It is immediate that both $A^{v}$ and $M^{e}$ are independent of $\lambda$ while the number of active firms $M$ rises in the quality of property rights protection. An increase in the measure of the agency parameter $b$ lowers $M^{e}$ and raises $A^{v}$. With Pareto-distributed productivity levels, the condition $M^{e}=\left(\varphi^{*}\right)^{-k} A$ delivers the cutoff productivity level that is independent of $\lambda$ and increasing in $b$. Figure 2 illustrates these relationships. The intuition for these results is straightforward. Financial development (lower $b$ ) allows some capitalists who were willing to enter as entrepreneurs, but were denied external finance, to credibly commit to diligent behavior. The number of entering firms increases and - due to a constant survival rate $\lambda$ - so does the number of active firms $M$. As more asset owners choose to found a company, more of this resource is needed for fixed investments and is therefore not available as an input in the production of intermediate goods.

Figure 2: CRedit CONSTRAints, ENTRY, AND PRODUCTIVITY

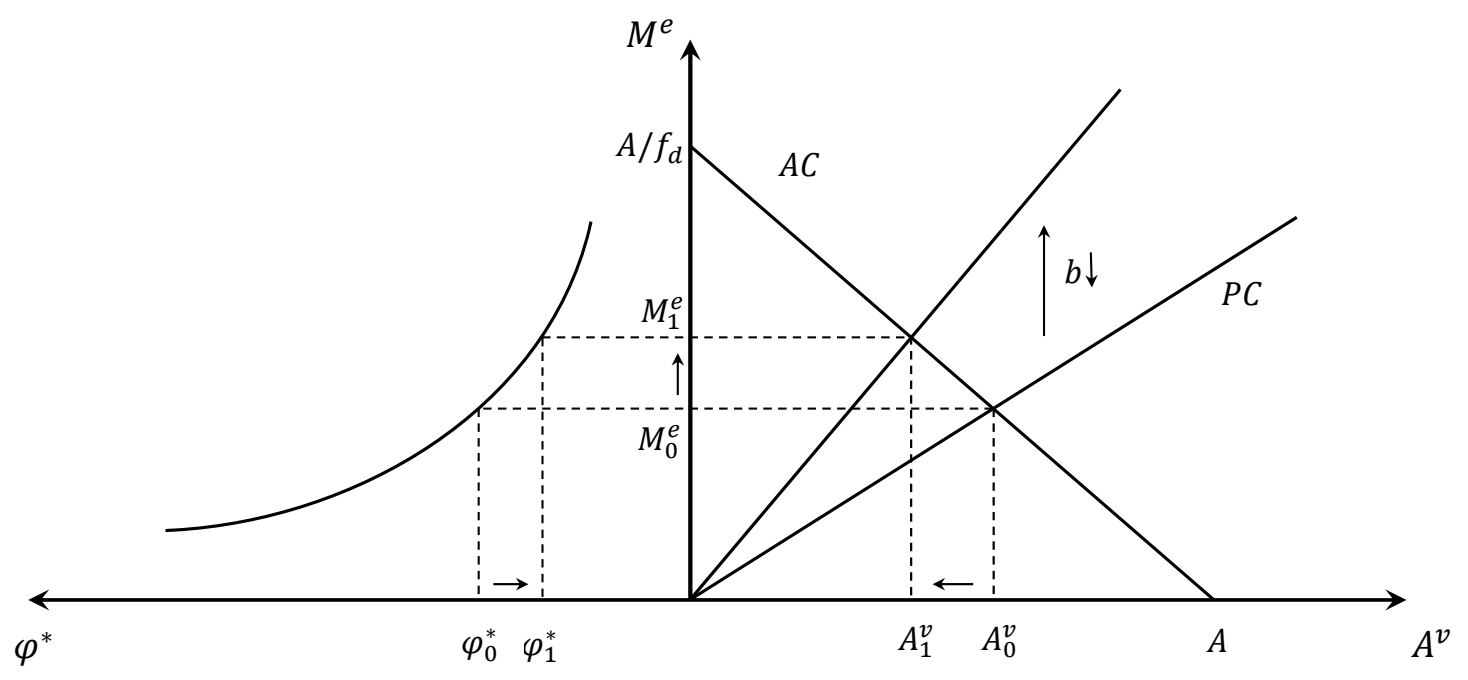




\subsection{Inequality}

We are now ready to discuss the role of financial development for inequality. To this end, we focus on two measures: wage inequality and the unemployment rate. ${ }^{12}$ To capture the effects on the distribution of wages, we compute the average wage of employed workers relative to the wage paid by the marginal (least productive) firm, ${ }^{13}$

$$
\frac{\bar{w}}{w\left(\varphi^{*}\right)}=\frac{k-\eta(1-\theta)}{k-\eta}
$$

The unemployment rate is given as

$$
U=1-\left(\frac{k}{k-\eta} \frac{\mu}{\sigma-1}\right)^{\theta}\left(\frac{M}{L}\right)^{\theta}\left[\frac{\bar{w}}{w\left(\varphi^{*}\right)}\right]^{-1}
$$

where $M$ needs to be substituted from (6) above. The following proposition summarizes the comparative-static insights with respect to these measures of inequality.

Proposition 1: Financial development, that is lower values of the agency cost parameter $b$, reduces unemployment while rendering relative wages unaffected.

Proof. These findings follow immediately from $\partial M / \partial b<0$.

Financial development affects employment through two channels in our model. First, a reduction of agency costs reduces average firm productivity implying that a given level of output requires more workers. Second, labor demand ceteris paribus declines due to a reduction in output. According to Proposition 1, the positive effect dominates unambiguously in the closed economy.

With respect to wage inequality, (7) reveals no influence of financial frictions. Intuitively, entry of new and less productive firms affects market shares of all firms proportionately, so the ratio of the marginal and the average wage remains constant. This outcome is of course driven by the assumption that firm productivity follows a Pareto distribution and not a general result. Nevertheless, it serves as a helpful reference point for the open economy effects where export selection plays a key role and helps to illustrate the economic mechanism.

\footnotetext{
${ }^{12}$ See Egger and Kreickemeier $(2009,2012)$ for similar approaches in the context of fair wages.

${ }^{13}$ Please refer to the online supplement for derivations.
} 


\section{The global economy}

We now extend the model by a second identical country to study the role of financial frictions in the global economy. We allow for international trade that faces two barriers: fixed foreign market entry costs and variable trade costs. In terms of notation, we distinguish between domestic firms, denoted by subscript $d$, and exporters (that also sell domestically), denoted by subscript $x$. Due to additional fixed costs for international trade, exporting firms require more assets as fixed investment than domestic firms, that is $f_{x}>f_{d}$. Variable costs are of the iceberg type implying that $\tau>1$ units have to be shipped in order for one unit to arrive abroad. Denoting by $r_{x}(\varphi)$ revenues of an exporting firm from domestic sales, total revenues of an exporter amount to $\Omega_{x} r_{x}(\varphi)$ with $1<1+\tau^{1-\sigma} \equiv \Omega_{x} \leq 2$. We refer to $\Omega_{x}$ as trade freeness.

\subsection{Credit constraints across firm types}

Depending on the firm type, each entrepreneur needs to secure $f_{\ell}-1$ units of capital, with $\ell \in\{d, x\}$. The incentive compatibility $(I C)$ constraint in the general form is given by

$$
\lambda\left[\frac{\Omega_{\ell} r_{\ell}(\varphi)}{\sigma}-T_{\ell}\right] \geq b
$$

with $\Omega_{d}=1$. Further, the lender will provide the loan if the manager is able to document a sufficiently high pledgable income. This participation constraint $(P C)$ requires that

$$
\lambda\left[\frac{\Omega_{\ell} r_{\ell}(\varphi)}{\sigma}-\frac{b}{\lambda}\right] \geq f_{\ell}-1
$$

Again, with a perfectly-competitive asset market, each entrepreneur offers a repayment $T_{\ell}$ that just satisfies the incentive compatibility constraint, that is $\left(f_{\ell}-1\right) / \lambda$. We can rewrite the participation constraint in a similar fashion as in autarky,

$$
\lambda \frac{\Omega_{\ell} r_{\ell}(\varphi)}{\sigma}=f_{\ell}-1+b
$$




\subsection{Export selection}

The marginal exporting firm is identified by productivity $\varphi_{x}^{*}$ that ensures equal profits under both organizational forms. Formally, this condition reads

$$
\frac{\Omega_{x} r_{x}\left(\varphi_{x}^{*}\right)}{\sigma}-\frac{f_{x}-1}{\lambda}=\frac{r_{d}\left(\varphi_{x}^{*}\right)}{\sigma}-\frac{f_{d}-1}{\lambda} .
$$

As operating profits are increasing in productivity $\varphi$, it is clear that the marginal exporter requires a higher productivity than the marginal domestic producer to cover the additional export fixed costs. Hence, the marginal exporter always satisfies the participation constraint and is thus not affected by credit rationing (see Ehrlich and Seidel, 2015).

To obtain the export propensity, we express $r_{x}$ in terms of $r_{d}$ in (9). For firms with identical productivity but different export status, we get from the fair-wage constraint

$$
\frac{w_{x}}{w_{d}}=\left(\frac{\Omega_{x} r_{x}}{r_{d}}\right)^{\theta}
$$

and from revenues

$$
\frac{\Omega_{x} r_{x}}{r_{d}}=\Omega_{x}\left(\frac{w_{x}}{w_{d}}\right)^{\mu(1-\sigma)} .
$$

Combing both expressions delivers

$$
\frac{w_{x}}{w_{d}}=\Omega_{x}^{\frac{\theta \eta}{\sigma-1}} \quad \text { and } \quad \frac{r_{x}}{r_{d}}=\Omega_{x}^{-\mu \theta \eta}
$$

Using $r_{d}\left(\varphi_{x}^{*}\right)=\left(\varphi_{x}^{*} / \varphi_{d}^{*}\right)^{\eta} r_{d}\left(\varphi_{d}^{*}\right)$ and the participation constraint $r_{d}\left(\varphi_{d}^{*}\right) / \sigma=\left(f_{d}-1+b\right) / \lambda$ jointly with the share of exporting firms, $\chi=\left[1-G\left(\varphi_{x}^{*}\right)\right] /\left[1-G\left(\varphi_{d}^{*}\right)\right]=\left(\varphi_{d}^{*} / \varphi_{x}^{*}\right)^{k}$, yields

$$
\chi=\left[\Phi^{-1}\left(\Omega_{x}^{\frac{\eta}{\sigma-1}}-1\right)\right]^{\frac{k}{\eta}},
$$

where $\Phi \equiv\left(f_{x}-f_{d}\right) /\left(f_{d}-1+b\right)$. To ensure $0 \leq \chi \leq 1$, we impose $\Phi>1$. As expected, $\chi$ is increasing in $f_{d}$ and trade freeness $\Omega_{x}$ and decreasing in export fixed costs $f_{x}$. Better access to external finance reduces the share of exporting firms because credit rationing only affects the least productive (non-exporting) firms. With more domestic firms in the market, $\chi$ necessarily has to decline. 


\subsection{Equilibrium}

To solve the open-economy equilibrium for $M^{e}, A^{v}$ and the domestic cutoff $\varphi_{d}^{*}$, we reformulate the participation constraint in the same way as in the closed economy version of the model. We obtain

$$
\frac{(1-\alpha) Y}{(1+\chi) M} \frac{k-\eta}{k} \frac{1+\chi}{1+\chi \Phi}=\frac{f_{d}-1+b}{\lambda},
$$

where the link between marginal and average productivity is now given by ${ }^{14}$

$$
\tilde{\varphi}=\left[\frac{k}{k-\eta} \frac{1+\chi \Phi}{1+\chi}\right]^{\frac{1}{\eta}} \varphi_{d}^{*}
$$

Export selection implies that the ratio between productivities of the average and the marginal firm is higher in the open economy compared to the closed economy.

We substitute $Y$ by making use of $A^{v}=\alpha(1-\mu) Y$ and combine (PCO) with the resource constraint for assets,

$$
A^{v}=A-M^{e}\left[f_{d}+\chi\left(f_{x}-f_{d}\right)\right],
$$

to obtain

$$
\begin{aligned}
A^{v} & =\frac{k(\sigma-1)(1-\mu)\left[\left(f_{d}-1+b\right)+\chi\left(f_{x}-f_{d}\right)\right]}{k(\sigma-1)(1-\mu)\left[\left(f_{d}-1+b\right)+\chi\left(f_{x}-f_{d}\right)\right]+\left[f_{d}+\chi\left(f_{x}-f_{d}\right)\right](k-\eta)} A \\
M^{e} & =\frac{k-\eta}{k(\sigma-1)(1-\mu)\left[\left(f_{d}-1+b\right)+\chi\left(f_{x}-f_{d}\right)\right]+\left[f_{d}+\chi\left(f_{x}-f_{d}\right)\right](k-\eta)} A .
\end{aligned}
$$

The productivity cutoff for a domestic firm is implied by $M^{e}=\left(\varphi_{d}^{*}\right)^{-k} A$ while the export cutoff is given by (10). In the global economy, financial development (lower $b$ ) is associated with both more firm entry and more active firms, with lower variable asset inputs $A^{v}$ and a lower productivity cutoff for domestic firms. In contrast, the export cutoff goes up, if agency costs decline. Although there is no direct effect on this threshold, financial development affects $\varphi_{x}^{*}$ in general equilibrium. A rise of the number of firms reduces the market share of incumbent firms such that the marginal exporter no longer gains from exporting and turns into a domestic firm. These selection effects will be key for the

\footnotetext{
${ }^{14}$ The derivation of average productivity follows the approach in Egger and Kreickemeier (2012).
} 
responses of wage inequality and unemployment.

\subsection{Inequality}

We start by discussing the role of trade liberalization and financial development for wage inequality. In the open economy, this measure is given by ${ }^{15}$

$$
\frac{\bar{w}}{w\left(\varphi_{d}^{*}\right)}=\frac{k-\eta(1-\theta)}{k-\eta} \frac{1+\chi \Phi}{1+\chi^{\frac{k-(1-\theta) \eta}{k}}\left(\Omega_{x}^{\frac{(1-\theta) \eta}{\sigma-1}}-1\right)} .
$$

As the second term is larger than one, wage inequality is higher in the open economy compared to autarky. Intuitively, selection into exporting by the most productive firms leads to a reallocation of revenues and profits between firms (Melitz, 2003). As exporters gain and domestic firms lose, the rent-sharing mechanism translates the increase in the heterogeneity of firm revenues into higher wage inequality. This insight also holds for marginal trade liberalization. ${ }^{16}$

Turning to the effects of financial development, we find that lowering agency costs generally has ambiguous effects on wage inequality in the open economy. First, reducing $b$ allows firm entry at the lower end of the productivity distribution. Notice that these companies pay the lowest wages in the market so $w\left(\varphi_{d}^{*}\right)$ declines unambiguously. If incumbent firms were not affected by this, this channel would increase wage inequality. However, incumbent firms are affected by entry as new firms reduce their market shares proportionally. Lower revenues lead to lower firm-specific wages of all firms which works towards a compression of the wage schedule and an unambiguous reduction in the average wage $\bar{w}$. This constitutes the second effect. Third, the least productive exporting firms find it no longer profitable to serve customers abroad. As the reduction in their market share reduces their operating profits, they can no longer cover export fixed costs. This status change also contributes to a reduction in $\bar{w}$.

\footnotetext{
${ }^{15}$ Derivations for this section are available in the online supplement.

${ }^{16}$ See online supplement for a proof of this result. It is noteworthy that our result differs somewhat from that in Egger and Kreickemeier (2012). While a marginal reduction in trade costs raises wage inequality unambiguously in our model, Egger and Kreickemeier (2012) find that trade liberalization raises wage inequality when the share of exporters is low and reduces it when the share of exporters is high. The key difference is that in our case the outside option of potential entrepreneurs is fixed in terms of the numeraire while in their paper it is the expected average wage across firms which is endogenously determined in general equilibrium.
} 
For financial development to reduce wage inequality, the decline in average wages has to be stronger than the decline in the marginal wage. It turns out that export selection plays an important role for understanding the effects. Recall that wage inequality was independent of credit constraints in autarky, as financial development led to a proportional reduction in both $w\left(\varphi_{d}^{*}\right)$ and $\bar{w}$. In the open economy, exporting firms pay a wage premium $w_{x} / w_{d}=\Omega^{\frac{\theta \eta}{\sigma-1}}$. Although it is independent of $b$, the discontinuity in the wage schedule becomes relevant for the distribution of wages if firms change their export status. In sum, wage inequality declines with financial development if the response at the exporter margin is sufficiently large such that the average wage declines more than the marginal wage.

What determines the magnitude of the response in $\chi$ ? First, the shape parameter of the Pareto distribution. If $k$ is low, there are relatively many firms with high productivity, so heterogeneity is high. In that case a reduction of $b$ leads to a relatively strong response in overall firm entry while the change in the export propensity is modest. Thus, the wage of the marginal firm declines more than the average wage, so wage inequality rises. In contrast, if $k$ is high, firms are more homogeneous with a higher density of low productivities. Now a reduction in $b$ leads to relatively little entry of new firms, but a comparably stronger reduction in the share of exporters. In this case, wage inequality declines with financial development.

Further, it can be inferred from (10) that the level of $\chi$ also matters for the magnitude of the response to $b$. We thus identify relative export market fixed costs $\Phi$ and trade freeness $\Omega$ as two additional determinants for the comparative static effects of financial development for wage inequality. High export market fixed costs and low trade freeness imply a low share of exporters rendering equity-enhancing effects of financial development more likely. The reason is that for an initially low level of exporters a status change of the marginal exporter implies a larger change in the share of exporters compared to a situation where relatively many firms export initially. Recall that $\chi$ is increasing in trade freeness $\Omega$ and decreasing in relative export fixed costs $\Phi$.

To illustrate this mechanism, we plot the partial derivative of wage inequality in $\Omega-\Phi-$ space for three distinct levels of $k$. The three functions in Figure 3 indicate the respective combinations of $\Omega$ and $\Phi$ where the effect of financial development on $\bar{w} / w\left(\varphi^{*}\right)$ is zero. Combinations of $\Omega$ and $\Phi$ in the bottom-right corner are associated with low levels of $\chi$ while the parameter combinations in the top-left corner imply a high export propensity. The area below the respective curves is associated with an equity-enhancing effect of 
financial development. As we increase $k$ sufficiently, the positive relationship holds for the entire parameter space. The following proposition summarizes our findings.

Proposition 2. Financial development reduces wage inequality if the distribution of firm productivities is sufficiently homogeneous (high $k$ ). When firm productivities are more heterogeneous (low $k$ ), better access to external finance raises wage inequality at high levels of $\chi$.

Proof. See Appendix A.

Figure 3: Wage INEQUALITY AND FINANCIAL DEVELOPMENT

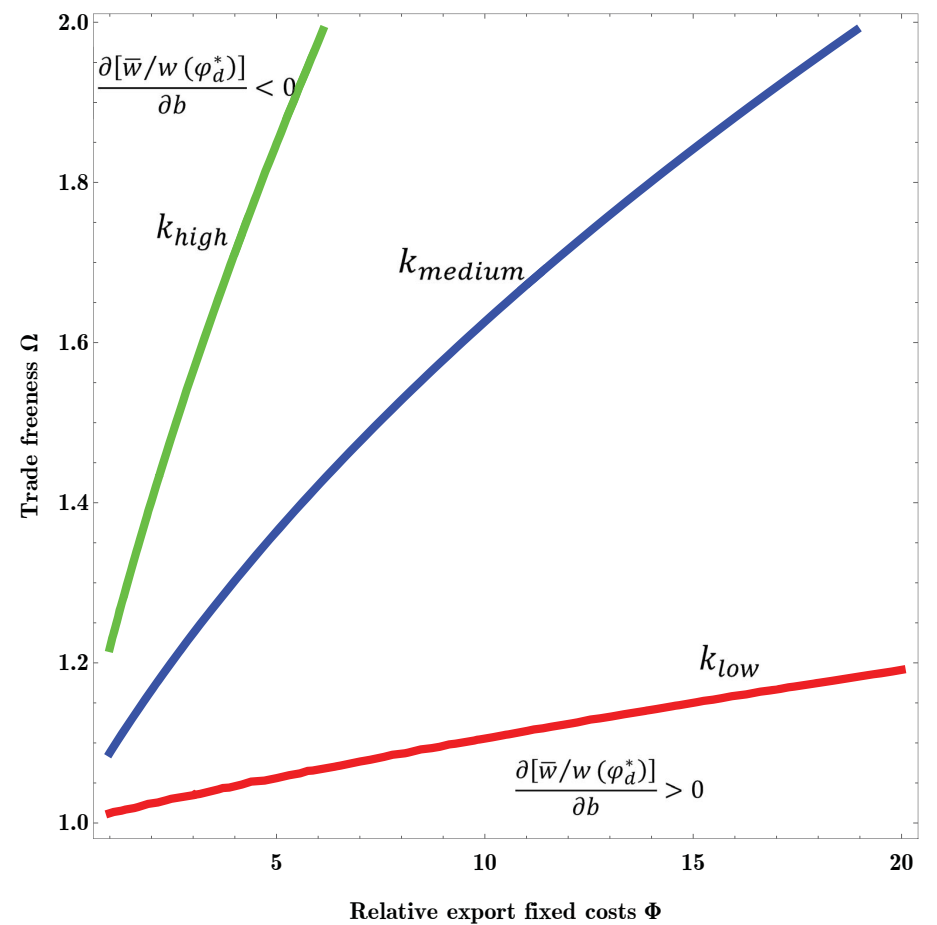

Note: The red, blue, and green line mark $\Omega-\Phi$ combinations where the partial derivative of wage inequality with respect to $b$ is equal to zero for different values of $k$. Note that $k$ represents the productivity distribution's shape parameter and we have set the elasticity of substitution $\sigma=3.8$ as in Bernard, Eaton, Jensen, and Kortum (2003), the labor share $\mu=0.7$, and the fair wage constraint $\theta=0.15$ as in Egger, Egger, Kreickemeier (2013). For the $\Omega-\Phi$ combinations below (above) the respective $\frac{\partial \bar{w} / w\left(\varphi^{*}\right)}{\partial b}=0$ lines financial development reduces (increases) wage inequality.

In sum, financial development stimulates entry of small firms which affects the size distribution of firms in general equilibrium. We have highlighted that better access to 
external finance also affects the export cutoff giving rise to changes in wage inequality in our model. There is sound evidence that small firms benefit more than proportionally from financial development (e.g. Aghion, Fally, and Scarpetta, 2007, Beck, DemirgüçKunt, Laeven, and Levine, 2008, or Beck, Demirgüç-Kunt, and Maksimovic, 2005) while there is mixed evidence on selection into exporting. While Manova (2013) argues that financial development raises the intensive and the extensive export margin, Goldbach and Nitsch (2015) do not find a statistically significant response of German exporting firms to tighter financial constraints.

We now take a closer look at the unemployment rate in the open economy. It is given by

$$
U=1-\left(\frac{k}{k-\eta} \frac{\mu}{\sigma-1}\right)^{\theta}\left[\frac{M(1+\chi \Phi)}{L}\right]^{\theta}\left[\frac{\bar{w}}{w\left(\varphi^{*}\right)}\right]^{-1},
$$

where $M$ needs to be substituted from above. Two insights are noteworthy. First, we observe that the unemployment rate in the global economy is unambiguously higher than in autarky. Highly productive firms raise their total profits by exporting so employees in these firms request higher wages (at full effort) due to the rent-sharing mechanism. As a consequence, the unemployment rate goes up. Second, we can show that trade liberalization raises unemployment monotonically. ${ }^{17}$

Turning to the role of financial development, we can build on the previous discussion on wage inequality adding the additional effect working through $M(1+\chi \Phi)$. In general, a reduction in agency costs exerts ambiguous effects on the unemployment rate as summarized in

Proposition 3. When firms are sufficiently homogeneous (high $k$ ) financial development reduces the unemployment rate. When firms are more heterogeneous (low $k$ ) and the share of exporters is high, financial development exerts opposite effects.

Proof. See Appendix B.

Financial development affects unemployment through two channels. First, it is immediate from (14) that there is a direct positive link between wage inequality and the unemployment rate. This is intuitive from the fair-wage constraint, because an increase in $\bar{w}$ raises the outside option of workers implying higher wage claims. For (4) to hold, the unemployment rate has to increase. Second, financial development raises the number of

\footnotetext{
${ }^{17}$ See online supplement for details.
} 
firms unambiguously and thereby labor demand. This effect contributes to a reduction in unemployment. In sum, if better access to external finance reduces wage inequality, then financial development clearly reduces the unemployment rate. If, however, a reduction in $b$ raises wage inequality, the overall effect on the unemployment rate depends on the relative magnitude of each channel.

\section{Conclusions}

In this paper, we have incorporated financial constraints into a trade model with labor market frictions to contrast the effects of financial development with those of trade liberalization. Similarly to insights from several recent papers in the trade-and-labor literature, trade liberalization can be shown to raise both wage inequality and unemployment in our model.

Financial development, in contrast, has ambiguous effects for inequality in general. The direction of change crucially depends on the size distribution of firms and on the costs of exporting. If firms are sufficiently homogeneous (a large number of small firms), improving access to external finance reduces wage inequality. If firms are more heterogeneous, however, wage inequality may increase if the costs of exporting are low. Moreover, we show that financial development has a positive effect on employment if it reduces wage inequality. However, for combinations of exporting costs and firm heterogeneity that imply a positive correlation between financial development and wage inequality, the overall effect on unemployment is ambiguous. In this case the sign of the correlation between financial development and unemployment depends on the amount of firm entry and the degree of wage inequality.

\section{References}

Acemoglu, D. and F. Zilibotti. 1997. Was Prometheus unbound by chance? Risk, diversification, and growth, Journal of Political Economy 105(4), 709-51.

Aghion, P., T. Fally and S. Scarpetta. 2007. Credit constraints as a barrier to the entry and post-entry growth of firms. Economic Policy 22(52). 733-779.

Akerlof, G.A. and J.L. Yellen. 1990. The fair-wage effort hypothesis and unemploy- 
ment. Quarterly Journal of Economics 105(2). 255-283.

Amiti, M. and D.R. Davis. 2012. Trade, firms, and wages: Theory and evidence. Review of Economic Studies 79(1). 1-36.

Antràs, P. and F.C. Foley. 2015. Poultry in motion: A study of international trade finance practices. Journal of Political Economy forthcoming.

Autor, D.H., Katz, L.F., and M.F. Kearney. 2008. Trends in U.S. wage inequality: revising the revisionists. Review of Economics and Statistics 90(2). 300-323.

Banerjee, A.V. and A.F. Newman. 1993. Occupational choice and the process of development. Journal of Political Economy 101(2). 274-298.

Beck, T., A. Demirgüç-Kunt, L. Laeven, and R. Levine. 2008. Finance, firm size, and growth. Journal of Money, Credit, and Banking 40(7). 1379-1405.

Beck, T., A. Demirgüç-Kunt, and V. Maksimovic. 2005. Financial and legal constraints to growth: Does firm size matter? Journal of Finance 60(1). 137-177.

Beck, T., A. Demirgüç-Kunt, and R. Levine. 2007. Finance, inequality and the poor. Journal of Economic Growth, 12. 27-49.

Bernard, A., J. Eaton, B. Jensen, S. Kortum. 2003. Plants and productivity in international trade. American Economic Review, 93(4). 1268-1290.

Bewley, T. 2005. Fairness, Reciprocity, and Wage Rigidity. In: Gintis, H., Bowles, S., Boyd, R., Fehr, E. (Eds.), Moral Sentiments and Material Interests: The Foundations of Cooperation in Economic Life. MIT Press, Cambridge/Mass., 303-338.

Clarke, G.R.G., L.C. Xu, and H. Zou. 2006. Finance and income inequality: what do the data tell us? Southern Economic Journal, 72, 578-596.

Egger, H., Egger, P., and U. Kreickemeier. 2013. Trade, wages, and profit. European Economic Review 64. 332-350.

Egger, P. and C. Keuschnigg. 2015. Innovation, trade, and finance. American Economic Journal: Microeconomics 7(2). 121-157.

Egger, H. and U. Kreickemeier. 2009. Firm heterogeneity and the labour market effects of trade liberalisation. International Economic Review 50(1). 187-261. 
Egger, H. and U. Kreickemeier. 2012. Fairness, trade, and inequality. Journal of International Economics 86(2). 184-196.

Ehrlich, M.v. and T. Seidel. 2015. Regional implications of financial market development: industry location and income inequality. European Economic Review $\mathbf{7 3 .}$ $85-102$

Fehr, E. and A. Falk. 1999. Wage rigidity in a competitive incomplete contract market. Journal of Political Economy 107(1). 106-134.

Foellmi, R. and M. Oechslin. 2010. Market imperfections, wealth inequality, and the distribution of trade gains. Journal of International Economics 81(1). 15-25.

Goldbach, S. and V. Nitsch. 2015. Cutting the credit line: Evidence from Germany. Discussion Paper No 25/2015, Deutsche Bundesbank.

Galor, O. and J. Zeira. 1993. Income distribution and macroeconomics. Review of Economic Studies 60(1). 35-52.

Helpman, E. and O. Itskhoki. 2010. Labor market rigidities, trade and unemployment. Review of Economic Studies 77(3). 1100-1137.

Helpman, E., O. Itskhoki, and S. Redding. 2010. Inequality and unemployment in a global economy. Econometrica 78(4). 1239-1283.

Holmstrom, B. and J. Tirole. 1997. Financial intermediation, loanable funds, and the real sector. Quarterly Journal of Economics 112(3). 663-691.

Howitt, P. 2002. Looking inside the labor market: a review article. Journal of Economic Literature 40(1). 125-138.

Ju, J. and S.-J. Wei. 2011. When is quality of financial system a source of comparative advantage? Journal of International Economics 84(2). 178-187.

Katz, L.F. and D.H. Autor. 1999. Changes in the wage structure and earnings inequality. In: Ashenfelter, O., Card, D. (Eds.), Handbook of Labor Economics, 3A. Amsterdam, Elsevier, pp. 1463-1555.

Krugman, P. 1979. Increasing returns, monopolistic competition, and international trade. Journal of International Economics 9(4). 469-479. 
Liang, Z. 2006. Financial development and income distribution: A system panel analysis with application to urban China. Journal of Economic Development 31(2). 1-21.

Manova, K. 2008. Credit constraints, equity market liberalizations and international trade. Journal of International Economics 76(1). 33-47.

Manova, K. 2013. Credit constraints, heterogeneous firms and international trade. Review of Economic Studies 80(2). 711-744.

Matsuyama, K. 2004. Financial market globalization, symmetry breaking and endogenous inequality of nations. Econometrica 72(3). 853-884.

Melitz, M.J. 2003. The impact of trade on intra-industry reallocations and aggregate industry productivity. Econometrica 71(6). 1695-1725.

Sampson, T. 2014. Selection into trade and wage inequality. American Economic Journal: Microeconomics 6(3). 157-202.

Schmidt-Eisenlohr, T. 2013. Towards a theory of trade finance. Journal of International Economics 91(1). 96-112.

World Trade Organization 2013. World Trade Report. Factors shaping the future of the world. Geneva. 


\section{Appendix}

\section{A Proof of Proposition 2}

The partial derivative with regard to $b$ is given by

$$
\frac{\partial \frac{\bar{w}}{w\left(\varphi^{*}\right)}}{\partial b}=\frac{k-\eta(1-\theta)}{k-\eta} \frac{\chi(k-\eta)}{\eta\left(f_{d}-1+b\right)\left[1+\chi^{\frac{k-\eta(1-\theta)}{k}}\left(\Omega_{x}^{\frac{\eta(1-\theta)}{\sigma-1}}-1\right)\right]^{2}} \Gamma
$$

where

$$
\Gamma \equiv \Phi^{1-\theta}\left\{\Phi^{\theta}-\left(\Omega_{x}^{\frac{\eta(1-\theta)}{\sigma-1}}-1\right)\left[\Phi^{-\frac{k-\eta}{\eta}} \frac{\eta \theta}{k-\eta}+\frac{k-\eta(1-\theta)}{\left(\Omega_{x}^{\frac{\eta}{\sigma-1}}-1\right)^{\frac{k}{\eta}}(k-\eta)}\right]\left(\Omega_{x}^{\frac{\eta}{\sigma-1}}-1\right)^{\frac{k-\eta(1-\theta)}{\eta}}\right\} .
$$

Since the first part of the expression is unambiguously positive, the sign of $\Gamma$ determines whether $\frac{\partial \frac{\bar{w}}{w\left(\varphi^{*}\right)}}{\partial b} \lessgtr 0$.

It is evident that $\Gamma$ is increasing in $\Phi$. The partial derivative with respect to $\Omega_{x}$ can be written as

$$
\begin{aligned}
\frac{\partial \Gamma}{\partial \Omega_{x}}= & \frac{\theta \eta}{\sigma-1} \Phi^{-\frac{k-\eta}{\eta}}\left(\Omega_{x}^{\frac{\eta}{\sigma-1}}-1\right)^{\frac{k-\eta(1-\theta)}{\eta}}\left[\frac{\eta(1-\theta)}{k-\eta}+\frac{k-\eta(1-\theta)}{k-\eta} \frac{\Omega_{x}^{\frac{\eta(1-\theta)}{\sigma-1}}-1}{\Omega_{x}^{\frac{\eta}{\sigma-1}}-1}\right] \\
& +\frac{k-\eta(1-\theta)}{k-\eta} \frac{\eta(1-\theta)}{\sigma-1}\left(\Omega_{x}^{\frac{\eta}{\sigma-1}}-1\right)^{-(1-\theta)} \Omega_{x}^{\frac{\eta}{\sigma-1}-1}\left(\Omega_{x}^{-\frac{\theta \eta}{\sigma-1}}-\frac{\Omega_{x}^{\frac{\eta(1-\theta)}{\sigma-1}}}{\Omega_{x}^{\frac{\eta}{\sigma-1}}}\right)>0
\end{aligned}
$$

Plugging these results into $\frac{\partial \Gamma}{\partial \Phi} d \Phi+\frac{\partial \Gamma}{\partial \Omega_{x}} d \Omega_{x}=0$ proofs that the slopes in Figure 3 must be unambiguously positive.

Moreover, as the sign of $\Gamma$ determines the partial derivative of wage inequality with regard to $b$ it suffices to show that $\frac{\partial \Gamma}{\partial k}>0$ in order to prove $\frac{\partial \bar{w} / w\left(\varphi^{*}\right)}{\partial b} / \partial k>0$. We can reformulate $\Gamma$ as 
$\Gamma=\Phi-\Phi^{1-\theta}\left(\Omega^{\frac{\eta(1-\theta)}{\sigma-1}}-1\right)\left[\frac{\eta \theta \Phi^{-\frac{k-\eta}{\eta}}}{k-\eta}\left(\Omega^{\frac{\eta(1-\theta)}{\sigma-1}}-1\right)^{\frac{k-\eta(1-\theta)}{\eta}}+\frac{k-\eta(1-\theta)}{\left(\Omega^{\frac{\eta(1-\theta)}{\sigma-1}}-1\right)^{1-\theta}(k-\eta)}\right]$

As $0<\left(\Omega^{\frac{\eta(1-\theta)}{\sigma-1}}-1\right)<1$ the first and second term in square brackets are clearly decreasing in $k$ such that $\frac{\partial \Gamma}{\partial k}>0$ is fulfilled. Accordingly, the lines in Figure 3 are shifted

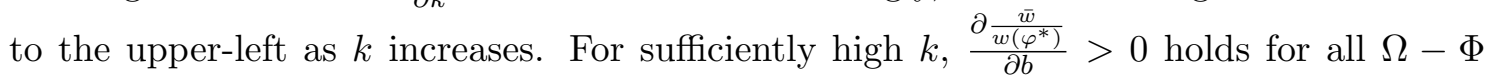
combinations.

\section{B Proof of Proposition 3}

The partial derivative is given by

$$
\frac{\partial U}{\partial b}=\left(\frac{k}{k-\eta} \frac{\mu}{\sigma-1}\right)^{\theta}\left\{-\frac{\partial[M(1+\chi \Phi)]^{\theta}}{\partial b} \times\left[\frac{\bar{w}}{w\left(\varphi^{*}\right)}\right]^{-1}+\frac{\partial \frac{\bar{w}}{\partial\left(\varphi^{*}\right)}}{\partial b}[M(1+\chi \Phi)]^{\theta}\right\}
$$

The second term in curly brackets is understood from Proposition 2 and generally ambiguous. The partial derivative of $[M(1+\chi \Phi)]^{\theta}$ is given by

$$
\begin{aligned}
\frac{\partial[M(1+\chi \Phi)]^{\theta}}{\partial b}= & \frac{\theta M^{\theta}(1+\chi \Phi)^{\theta-1}}{k(\sigma-1)(1-\mu)\left[\left(f_{d}-1+b\right)+\chi\left(f_{x}-f_{d}\right)\right]+\left[f_{d}+\chi\left(f_{x}-f_{d}\right)\right](k-\eta)} \times \\
& \left\{\frac{k-\eta}{\eta} \chi \Phi\left[k(\sigma-1)(1-\mu)(1+\chi \Phi)+\left(\frac{f_{d}}{f_{d}-1+b}+\chi \Phi\right)(k-\eta)\right]\right. \\
& \left.-\left[k(\sigma-1)(1-\mu)\left(1+\frac{k}{\eta} \chi \Phi^{2}\right)+\frac{k}{\eta} \chi \Phi^{2}(k-\eta)\right](1+\chi \Phi)\right\}<0
\end{aligned}
$$

To see this, we rearrange the expressions in curly brackets to get

$$
\begin{array}{r}
-k(\sigma-1)(1-\mu)(1+\chi \Phi)\left[1+\frac{k}{\eta} \chi \Phi^{2}-\frac{k-\eta}{\eta} \chi \Phi\right] \\
+(k-\eta)\left[\left(\frac{f_{d}}{f_{d}-1+b}+\chi \Phi\right)\left(\frac{k-\eta}{\eta} \chi \Phi\right)-\frac{k}{\eta} \chi \Phi^{2}(1+\chi \Phi)\right] .
\end{array}
$$

The first row is clearly negative as $\Phi>1$. The second line is unambiguously negative because $1+\chi \Phi>f_{d} /\left(f_{d}-1+b\right)+\chi \Phi($ as $b>1)$ and $(k / \eta) \chi \Phi^{2}>[(k-\eta) / \eta] \chi \Phi$. Thus, if 
$\partial\left[(\bar{w}) /\left(w\left(\varphi^{*}\right)\right] / \partial b\right.$ is positive, the effect on unemployment is fostered through firm entry. If $\partial\left[(\bar{w}) /\left(w\left(\varphi^{*}\right)\right] / \partial b\right.$ is negative, the effect on unemployment is mitigated through the positive effect on unemployment from firm entry. 


\section{Supplement}

\section{Derivation of average productivity}

We follow Egger and Kreickemeier (2012) in computing average productivity from the price index equation. In our case, we have for the global economy:

$$
P^{1-\sigma}=\frac{A}{M(1+\chi)}\left[\int_{\varphi_{d}^{*}}^{\varphi_{x}^{*}} p_{d}(\varphi)^{1-\sigma} \lambda g(\varphi) d \varphi+\Omega_{x} \int_{\varphi_{x}^{*}}^{\infty} p_{x}(\varphi)^{1-\sigma} \lambda g(\varphi) d \varphi\right]
$$

Note that the density is corrected for the success rate $\lambda$. Using the following links: (i) $\left[p_{d}(\varphi) / p_{d}(\tilde{\varphi})\right]^{1-\sigma}=r(\varphi) / r(\tilde{\varphi})=(\varphi / \tilde{\varphi})^{\eta}$, (ii) $\left[p_{x}(\varphi) / p_{d}(\varphi)\right]^{1-\sigma}=r_{x}(\varphi) / r_{d}(\varphi)=\Omega_{x}^{-\mu \theta \eta}$, (iii) $P=1$, and (iv) $A\left(\varphi_{d}^{*}\right)^{-k}=M^{e}=M / \lambda$ delivers

$$
\begin{aligned}
& 1=\frac{A}{\lambda M^{e}(1+\chi)} p_{d}(\tilde{\varphi})\left[\int_{\varphi_{d}^{*}}^{\varphi_{x}^{*}}\left(\frac{\varphi}{\tilde{\varphi}}\right)^{\eta} \lambda k \varphi^{-k-1} d \varphi+\Omega_{x}^{\frac{\eta}{\sigma-1}} \int_{\varphi_{x}^{*}}^{\infty}\left(\frac{\varphi}{\tilde{\varphi}}\right)^{\eta} \lambda k \varphi^{-k-1} d \varphi\right] \\
& 1=\frac{\left(\varphi_{d}^{*}\right)^{k}}{(\tilde{\varphi})^{\eta}} \frac{k}{k-\eta} \frac{1}{1+\chi}\left\{\left[-\varphi^{\eta-k}\right]_{\varphi_{d}^{*}}^{\varphi_{x}^{*}}+\Omega_{x}^{\frac{\eta}{\sigma-1}}\left[-\varphi^{\eta-k}\right]_{\varphi_{x}^{*}}^{\infty}\right\} \\
& 1=\frac{\left(\varphi_{d}^{*}\right)^{k}}{(\tilde{\varphi})^{\eta}} \frac{k}{k-\eta} \frac{1}{1+\chi}\left[\left(\varphi_{d}^{*}\right)^{\eta-k}-\left(\varphi_{x}^{*}\right)^{\eta-k}+\Omega_{x}^{\frac{\eta}{\sigma-1}}\left(\varphi_{x}^{*}\right)^{\eta-k}\right]
\end{aligned}
$$

Using the export propensity $\chi=\left[\left(\varphi_{d}^{*}\right) /\left(\varphi_{x}^{*}\right)\right]^{k}$, we get

$$
1=\left(\frac{\varphi_{d}^{*}}{\tilde{\varphi}}\right)^{\eta} \frac{k}{k-\eta} \frac{1}{1+\chi}\left[1+\chi\left(\frac{\varphi_{x}^{*}}{\varphi_{d}^{*}}\right)^{\eta}\left(\Omega^{\frac{\eta}{\sigma-1}}-1\right)\right]
$$

Plugging in $\Omega_{x}^{\frac{\eta}{\sigma-1}}-1$ from (10) yields

$$
\tilde{\varphi}=\left[\frac{k}{k-\eta} \frac{1+\chi \Phi}{1+\chi}\right]^{\frac{1}{\eta}} \varphi_{d}^{*}
$$

\section{Derivation of unemployment rate $U$}

Closed economy: 
We obtain the employment rate by solving

$$
(1-U) L=A \int_{\varphi^{*}}^{\infty} l(\varphi) \lambda d G(\varphi)=\frac{M^{e}}{1-G\left(\varphi^{*}\right)} \int_{\varphi^{*}}^{\infty} l(\varphi) \lambda d G(\varphi)
$$

Replacing $l(\varphi)$ by using $l(\varphi) w(\varphi)=\alpha \mu r(\varphi)$ delivers

$$
\frac{l(\varphi)}{l(\tilde{\varphi})}=\frac{w(\tilde{\varphi})}{w(\varphi)} \frac{r(\varphi)}{r(\tilde{\varphi})}=\left(\frac{\tilde{\varphi}}{\varphi}\right)^{\theta \eta}\left(\frac{\tilde{\varphi}}{\varphi}\right)^{-\eta}=\left(\frac{\varphi}{\tilde{\varphi}}\right)^{\eta(1-\theta)}
$$

Inserting into the integral equation yields

$$
\begin{aligned}
(1-U) L & =\left(\varphi^{*}\right)^{k} \operatorname{Ml}(\tilde{\varphi})(\tilde{\varphi})^{-\eta(1-\theta)} k \int_{\varphi^{*}}^{\infty} \varphi^{\eta(1-\theta)} \varphi^{-k-1} d \varphi \\
& =\frac{k}{k-\eta(1-\theta)} \operatorname{Ml}(\tilde{\varphi})\left(\frac{\varphi^{*}}{\tilde{\varphi}}\right)^{\eta(1-\theta)} \\
& =\frac{k}{k-\eta(1-\theta)}\left(\frac{k-\eta}{k}\right)^{1-\theta} \operatorname{Ml}(\tilde{\varphi})
\end{aligned}
$$

In a next step, we replace $l(\tilde{\varphi})$ by using the same link from above for the average firm $l(\tilde{\varphi})=\alpha \mu r(\tilde{\varphi}) / w(\tilde{\varphi})$. We know that $r(\tilde{\varphi})=Y / M$ and we get $w(\tilde{\varphi})$ from the fair wage constraint. We replace $r(\tilde{\varphi}) / \sigma$ by $(1-\alpha) Y / M$ and $(1-U) \bar{w}$ by $\alpha \mu Y / L$ to get

$$
w(\tilde{\varphi})=\left(\frac{1-\alpha}{M}\right)^{\theta}\left(\frac{\alpha \mu}{L}\right)^{1-\theta} Y
$$

Substituting yields (8).

Open economy:

In the open economy, we need to solve

$$
(1-U) L=A\left[\int_{\varphi_{d}^{*}}^{\varphi_{x}^{*}} l_{d}(\varphi) \lambda d G(\varphi)+\Omega_{x} \int_{\varphi_{x}^{*}}^{\infty} l_{x}(\varphi) \lambda d G(\varphi)\right]
$$

Using $M^{e}=\left(\varphi_{d}^{*}\right)^{-k} A$ and $M=\lambda M^{e}$ yields

$$
(1-U) L=\left(\varphi_{d}^{*}\right)^{k} M\left[\int_{\varphi_{d}^{*}}^{\varphi_{x}^{*}} l_{d}(\varphi) d G(\varphi)+\Omega_{x} \int_{\varphi_{x}^{*}}^{\infty} l_{x}(\varphi) d G(\varphi)\right]
$$

We now follow the same steps as in the closed economy section. For the domestic part, 
we use

$$
\frac{l_{d}(\varphi)}{l_{d}(\tilde{\varphi})}=\frac{w(\tilde{\varphi})}{w(\varphi)} \frac{r_{d}(\varphi)}{r(\tilde{\varphi})}=\left(\frac{\varphi}{\tilde{\varphi}}\right)^{\eta(1-\theta)}
$$

and for the export part we use

$$
\frac{l_{x}(\varphi)}{l_{d}(\varphi)}=\frac{w_{d}(\varphi)}{w_{x}(\varphi)} \frac{r_{x}(\varphi)}{r_{d}(\varphi)}=\Omega_{x}^{-\frac{\theta \eta}{\sigma-1}} \Omega_{x}^{-\mu \theta \eta}
$$

in combination with the substitution for $l_{d}(\varphi)$. This delivers

$$
\begin{aligned}
(1-U) L & =\left(\varphi_{d}^{*}\right)^{k} M\left[\int_{\varphi_{d}^{*}}^{\varphi_{x}^{*}}\left(\frac{\varphi}{\tilde{\varphi}}\right)^{\eta(1-\theta)} k \varphi^{-k-1} d \varphi+\Omega_{x}^{\frac{(1-\theta) \eta}{\sigma-1}} \int_{\varphi_{x}^{*}}^{\infty}\left(\frac{\varphi}{\tilde{\varphi}}\right)^{\eta(1-\theta)} k \varphi^{-k-1} d \varphi\right] \\
& =\left(\varphi_{d}^{*}\right)^{k}(\tilde{\varphi})^{-\eta(1-\theta)} M l_{d}(\tilde{\varphi})\left[\left|\frac{-k}{k-\eta(1-\theta)} \varphi^{\eta(1-\theta)-k}\right|_{\varphi_{d}^{*}}^{\varphi_{x}^{*}}+\Omega_{x}^{\frac{(1-\theta) \eta}{\sigma-1}}\left|\frac{-k}{k-\eta(1-\theta)} \varphi^{\eta(1-\theta)-k}\right|_{\varphi_{x}^{*}}^{\infty}\right] \\
& =\frac{k}{k-\eta(1-\theta)}\left(\varphi_{d}^{*}\right)^{k}(\tilde{\varphi})^{-\eta(1-\theta)} M l_{d}(\tilde{\varphi})\left[\left(\varphi_{d}^{*}\right)^{\eta(1-\theta)-k}-\left(\varphi_{x}^{*}\right)^{\eta(1-\theta)-k}+\Omega_{x}^{\frac{(1-\theta) \eta}{\sigma-1}}\left(\varphi_{x}^{*}\right)^{\eta(1-\theta)-k}\right] \\
& =\frac{k}{k-\eta(1-\theta)}\left(\frac{\varphi_{d}^{*}}{\tilde{\varphi}}\right)^{\eta(1-\theta)} M l_{d}(\tilde{\varphi})\left[1+\left(\Omega_{x}^{\frac{(1-\theta) \eta}{\sigma-1}}-1\right) \chi\left(\frac{\varphi_{x}^{*}}{\varphi_{d}^{*}}\right)^{\eta(1-\theta)}\right] \\
& =\frac{k}{k-\eta(1-\theta)}\left(\frac{\varphi_{d}^{*}}{\tilde{\varphi}}\right)^{\eta(1-\theta)}(1+\chi) M l_{d}(\tilde{\varphi}) \frac{\chi^{\frac{k-\eta(1-\theta)}{k}}}{\left(\Omega_{x}^{\frac{(1-\theta) \eta}{\sigma-1}}-1\right)}
\end{aligned}
$$

To replace $l_{d}(\tilde{\varphi})$, we use $l_{d}(\tilde{\varphi}) w_{d}(\tilde{\varphi})=\alpha \mu r_{d}(\tilde{\varphi})$ and substitute $r_{d}(\tilde{\varphi})=Y / M(1+\chi)$ to get

$$
l(\tilde{\varphi})=\frac{\alpha \mu Y}{M(1+\chi) w(\tilde{\varphi})} .
$$

The wage paid by the average firm can be obtained from the fair-wage constraint where we substitute as above

$$
w(\tilde{\varphi})=\left[\frac{(1-\alpha) Y}{(1+\chi) M}\right]^{\theta}\left[\frac{\alpha \mu Y}{L}\right]^{1-\theta}=\left(\frac{1-\alpha}{\alpha \mu}\right)^{\theta}\left(\frac{L}{(1+\chi) M}\right)^{\theta} \frac{Y}{L} \alpha \mu
$$

Plugging in delivers

$$
(1+\chi) M l_{d}(\tilde{\varphi})=L\left(\frac{\alpha \mu}{1-\alpha}\right)^{\theta}\left(\frac{(1+\chi) M}{L}\right)^{\theta}
$$


Combining all parts delivers (14).

\section{Derivation of $\bar{w} / w\left(\varphi_{d}^{*}\right)$}

\section{Closed economy:}

To derive this expression, we start from the fair-wage constraint for the marginal firm:

$$
w\left(\varphi_{d}^{*}\right)=\left[\frac{r_{d}\left(\varphi_{d}^{*}\right)}{\sigma}\right]^{\theta}[(1-U) \bar{w}]^{1-\theta} .
$$

We substitute operating profits of the marginal firm by using the fact that $r\left(\varphi^{*}\right) / \sigma=$ $\frac{k-\eta}{k}(1-\alpha) Y / M$ and $(1-U) \bar{w}=\alpha \mu Y / L$. This brings

$$
w\left(\varphi_{d}^{*}\right)=\left(\frac{k-\eta}{k}\right)^{\theta}\left(\frac{1-\alpha}{\alpha \mu}\right)^{\theta} \alpha \mu\left(\frac{L}{M}\right)^{\theta} \frac{Y}{L} .
$$

Further, we can write

$$
\frac{(1-U) \bar{w}}{w\left(\varphi^{*}\right)}=\frac{\alpha \mu \frac{Y}{L}}{\left(\frac{k-\eta}{k}\right)^{\theta}\left(\frac{1-\alpha}{\alpha \mu}\right)^{\theta} \alpha \mu\left(\frac{L}{M}\right)^{\theta} \frac{Y}{L}}=\left(\frac{k}{k-\eta}\right)^{\theta}\left(\frac{\alpha \mu}{1-\alpha}\right)^{\theta}\left(\frac{M}{L}\right)^{\theta}
$$

Dividing by $1-U$ yields (7).

Open economy:

From the fair-wage constraint, we have

$$
w\left(\varphi_{d}^{*}\right)=\left[\frac{r_{d}\left(\varphi_{d}^{*}\right)}{\sigma}\right]^{\theta}[(1-U) \bar{w}]^{1-\theta} .
$$

We are replacing

$$
\frac{r_{d}\left(\varphi_{d}^{*}\right)}{\sigma}=\frac{(1-\alpha) Y}{(1+\chi) M} \frac{k-\eta}{k} \frac{1+\chi}{1+\chi \Phi}
$$


and $(1-U) \bar{w}$ by $\alpha \mu Y / L$ to get

$$
w\left(\varphi_{d}^{*}\right)=\left(\frac{1-\alpha}{\alpha \mu} \frac{k-\eta}{k}\right)^{\theta}\left[\frac{L}{M(1+\chi \Phi)}\right]^{\theta} \alpha \mu \frac{Y}{L} .
$$

Then, we can express

$$
\begin{aligned}
\frac{(1-U) \bar{w}}{w\left(\varphi_{d}^{*}\right)} & =\frac{\alpha \mu \frac{Y}{L}}{\left(\frac{1-\alpha}{\alpha \mu} \frac{k-\eta}{k}\right)^{\theta}\left[\frac{L}{M(1+\chi \Phi)}\right]^{\theta} \alpha \mu \frac{Y}{L}} \\
& =\left(\frac{\alpha \mu}{1-\alpha} \frac{k}{k-\eta}\right)^{\theta}\left[\frac{M(1+\chi \Phi)}{L}\right]^{\theta}
\end{aligned}
$$

Dividing both sides by $1-U$ brings (13).

\section{Comparing inequality measures in autarky and in the global economy}

With respect to wage inequality, it is sufficient to show that the second term in (13) is larger than unity. This is satisfied if

$$
\Phi>\chi^{\frac{-(1-\theta) \eta}{k}}\left(\Omega_{x}^{\frac{(1-\theta) \eta}{\sigma-1}}-1\right)
$$

Plugging in $\chi$ and simplifying yields

$$
\frac{\left(\Omega_{x}^{\frac{\eta}{\sigma-1}}-1\right)^{1-\theta}}{\Omega_{x}^{\frac{(1-\theta) \eta}{\sigma-1}}-1}>\Phi^{-\theta} .
$$

Straightforward calculations clarify that the left-hand side is larger than one because

$$
\begin{gathered}
\Omega_{x}^{\frac{(1-\theta) \eta}{\sigma-1}}-(1-\theta) \Omega_{x}^{\frac{\eta}{\sigma-1}}+1>\Omega_{x}^{\frac{(1-\theta) \eta}{\sigma-1}}-1 \\
\Rightarrow(1-\theta) \Omega_{x}^{\frac{\eta}{\sigma-1}}<\frac{2}{1-\theta},
\end{gathered}
$$

and the right-hand side is smaller than one from $\Phi>1$.

Turning to the employment rate, we know from the discussion above that the last term in $(1-U)^{o}$ is smaller than one. It is thus sufficient to show that $M^{o}(1+\chi \Phi)<M^{a}$, where 
superscripts $o$ and $a$ refer to autarky and the open economy. Building on the respective number-of-firms equations, we obtain the condition

$$
\frac{f_{d}}{f_{d}-1+b}(1+\chi \Phi)<\frac{f_{d}}{f_{d}-1+b}+\chi \Phi
$$

which is satisfied as $b>1$.

\section{Inequality and trade liberalization}

We first show that wage inequality unambiguously increases with trade liberalization.

The partial derivative with regard to $\Omega$ is given by:

$$
\frac{\partial \frac{\bar{w}}{w\left(\varphi^{*}\right)}}{\partial \Omega}=\frac{\Omega^{\frac{\eta}{\sigma-1}}[k-\eta(1-\theta)] \chi^{\frac{k-\eta}{k}}}{(\sigma-1) \Omega(k-\eta)\left[\left(\Omega^{\frac{\eta(1-\theta)}{\sigma-1}}-1\right) \chi^{\frac{k-\eta(1-\theta)}{k}}+1\right]^{2}} \Psi>0
$$

where

$$
\Psi=k\left[1-\frac{1}{\Phi}\left(\Omega^{\frac{\eta(1-\theta)}{\sigma-1}}-1\right) \chi^{\frac{\eta(\theta-1)}{k}}\right]-\eta(1-\theta)\left(\frac{1}{\Phi}+\chi\right)\left(1-\Omega^{-\frac{\eta \theta}{\sigma-1}}\right) \chi^{\frac{\eta(\theta-1)}{k}}
$$

The first part of $\frac{\partial \frac{\bar{w}}{\partial\left(\varphi^{*}\right)}}{\partial \Omega}$ is unambiguously positive. Moreover, straightforward but tedious reformulation of $\Psi$ proofs that $\Psi>0$ for $\Phi \geq 1$ which corresponds to the parameter constraint required for the export propensity to range between zero and unity. The latter can be shown in two steps: (i) the first part of $\Psi$ is strictly bigger than the second part for $\Phi=1$; (ii) the first part of $\Psi$ monotonically increases in $\Phi$ whereas the second part monotonically decreases in $\Phi$.

Turning to the unemployment rate, the partial derivative reads

$$
\frac{\partial U}{\partial \Omega_{x}}=\left(\frac{k}{k-\eta} \frac{\mu}{\sigma-1}\right)^{\theta}\left\{-\frac{\partial[M(1+\chi \Phi)]^{\theta}}{\partial \Omega_{x}} \times\left[\frac{\bar{w}}{w\left(\varphi^{*}\right)}\right]^{-1}+\frac{\partial \frac{\bar{w}}{w\left(\varphi^{*}\right)}}{\partial \Omega_{x}}[M(1+\chi \Phi)]^{\theta}\right\} .
$$

We know from the discussion above that the second term is unambiguously positive. We 
define $\tilde{\Omega}_{x} \equiv \Omega_{x}^{\frac{\eta}{\sigma-1}-1} /\left(\Omega_{x}^{\frac{\eta}{\sigma-1}}-1\right)$ and turn to the first expression:

$$
\frac{\partial[M(1+\chi \Phi)]^{\theta}}{\partial \Omega_{x}}=-\frac{\theta M^{1+\theta}(1+\chi \Phi)^{\theta-1}}{\lambda A} \frac{k}{\sigma-1} \chi \Phi \tilde{\Omega}_{x}(b-1)<0
$$

as $b>1$ holds.

We can thus conclude that trade liberalization (an increase in $\Omega_{x}$ ) unambiguously raises the unemployment rate. 